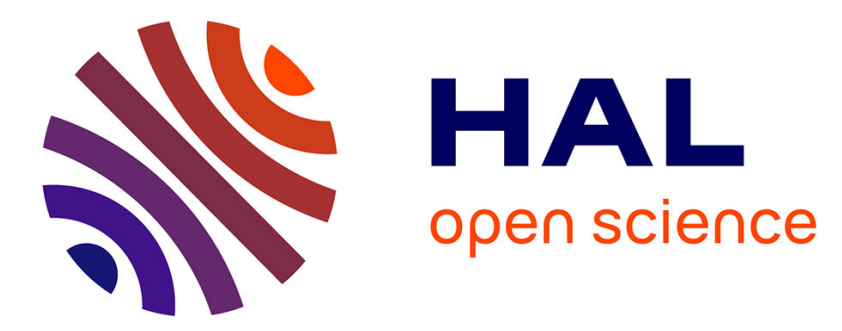

\title{
Landscape regularity modelling for environmental challenges in agriculture
}

El Ghali Lazrak, Jean-Francois Mari, Benoît Marc

\section{To cite this version:}

El Ghali Lazrak, Jean-Francois Mari, Benoît Marc. Landscape regularity modelling for environmental challenges in agriculture. Landscape Ecology, 2009, Landscape Ecology, 25 (2), pp.169-183. 10.1007/s10980-009-9399-8 . inria-00419952

\section{HAL Id: inria-00419952 \\ https://hal.inria.fr/inria-00419952}

Submitted on 25 Sep 2009

HAL is a multi-disciplinary open access archive for the deposit and dissemination of scientific research documents, whether they are published or not. The documents may come from teaching and research institutions in France or abroad, or from public or private research centers.
L'archive ouverte pluridisciplinaire HAL, est destinée au dépôt et à la diffusion de documents scientifiques de niveau recherche, publiés ou non, émanant des établissements d'enseignement et de recherche français ou étrangers, des laboratoires publics ou privés. 


\title{
Landscape regularity modelling for environmental challenges in agriculture
}

\author{
El Ghali Lazrak * Jean-François Mari ${ }^{\dagger} \quad$ Marc Benoît ${ }^{\ddagger}$
}

\begin{abstract}
In agricultural landscapes, methods to identify and describe meaningful landscape patterns play an important role to understand the interaction between landscape organization and ecological processes. We propose an innovative stochastic modelling method of agricultural landscape organization where the temporal regularities in land-use are first identified through recognized Land-Use Successions (LUS) before locating these successions in landscapes. These time-space regularities within landscapes are extracted using a new data mining method based on Hidden Markov Models. We applied this methodological proposal to the Niort Plain (West of France). We built a temporo-spatial analysis for this case study through spatially explicit analysis of Land Use Succession (LUS) dynamics. Implications and perspectives of such an approach, which links together the temporal and the spatial dimensions of the agricultural organization, are discussed by assessing the relationship between the agricultural landscape patterns defined using this approach and ecological data through an illustrative example of bird nests.
\end{abstract}

Keywords Cropping system $\bullet$ Land-Use Changes $\bullet$ Temporo-spatial analysis $\bullet$ Data mining $\bullet$ Hidden Markov Model (HMM) • Hierarchical Hidden Markov Model (HHMM) • Landscape Agronomy • Agricultural patterns - Landscape Ecology • Poitou-Charentes (France)

The original publication is available at www.springerlink.com, Landscape Ecology Modelling, DOI 10.1007/s10980-009-9399-8

\footnotetext{
*INRA, UR 055, SAD ASTER, 662, avenue Louis Buffet F-88500 Mirecourt, France email: lazrak@mirecourt.inra.fr (Corresponding author)

${ }^{\dagger}$ UMR-CNRS 7503 LORIA, B.P. 239, F-54506 Vandœuvre-lès-Nancy, France e-mail: jfmari@loria.fr

${ }^{\ddagger}$ INRA, UR 055, SAD ASTER, 662, avenue Louis Buffet F-88500 Mirecourt, France email: benoit@mirecourt.inra.fr
} 


\section{Introduction}

Agroecosystems are the major mode of land-use both at French (52\%) and European (42\%) levels. Since 1962, under the influence of the Common Agricultural Policy, agricultural production has intensified and its effects on biodiversity are no longer a matter of debate (Donald et al. 2001 ; Robinson and Sutherland 2002). Biodiversity conservation and restoration have become a social necessity and a political goal. Yet the practical means to achieve them in agroecosystems are still to be developed (Turner 2005 ; Butler et al. 2007). To understand the interaction between landscape organization and ecological processes, one needs to identify and quantify landscape patterns in meaningful ways (Turner 1990).

In agricultural landscapes, land-uses are heterogeneously distributed among different polygons (agricultural parcels). They also display dynamic patterns as a result of crop cycles, agricultural practices and other driving forces of land-use changes.

Recent studies (Rétho et al. 2008) have investigated the relationship of restricted areas of agricultural landscape with the diversity of animal species. On wider areas the complexity of agricultural landscapes needs to be simplified before investigating the relationships between a set of landscape indices (predictor variables) and ecological variables. This complexity of agricultural landscapes is generally simplified by using coarse agricultural land-use classes (e.g. Poudevigne and Alard 1997; Donald et al. 2001 ; Fuller et al. 2005). In this paper, we introduce a method which takes into account greater agricultural knowledge to identify and describe agricultural patterns. This description of agricultural patterns could improve the assessment of biodiversity in agricultural ecosystems at small geographical scales, and the assessment of water resource degradation in agricultural regions (Mignolet et al. 2007).

Agricultural biodiversity is related to soil, climate and cropping system interactions (Forman and Godron 1986). We focused on the factors managed and driven by farmers. For us, they correspond to cropping systems, which were categorized by Sebillotte (1974) into two components : (i) crop successions, seen as the ordered sequences of soil occupancy in each field and (ii) technical sequences, defined as the ordered sequences of cultural practices on a crop for production.

This research falls within the realm of landscape agronomy, the aim of which is to study the organization of farming activities on small geographical scales (Benoit et al. 2007). Its scope is at the conjunction where technical farming activities in the fields, the influence of EU and world regulations 
impact on agriculture. We now see an increasing attention being given to local issues as result of farming activities and environmental preservation in particular. Landscape agronomy as an emerging discipline combines the concepts and methods of both (i) geographers and (ii) agronomists (Benoît and Papy 1997), by respectively combining the following :

1. multi-scale modelling for land-use changes and for the investigation into territorial consistencies (Velkamp and fresco 1997; De Loning et al. 1999); and

2. analytical methods to describe the reasoning behind the way regional agricultural systems work. These methods notably rely on the construction and then on the spatialization of farming classifications (Perrot 1990 ; Landais 1996; Mignolet and Benoît 2001; Leisz et al. 2005 ; Mignolet et al. 2007).

The way a farmer organizes his territory is a time and spatial process. The land-use category of a given site depends upon the land-use categories of the neighbourhood. For example, grasslands are mainly located in areas close to villages, whereas maize fields are usually far away from forests. The Markov Random Field (MRF) is an elegant mathematical model to take into account the uncertainty of locations in the vicinity of a given place. This model clusters the territory into patches where the distribution of land-use categories follows a certain probability law. On the other hand, the landuse category at time $t$ (the current year is the usually admitted time slot unit) for a field depends also upon its former category at time $t-1, t-2$, etc. Since the late nineteenth century, plant successions have been studied on vegetation dynamics of natural ecosystems as reviewed by Glenn-Lewin and van der Maarel (1992). Among several approaches for studying vegetation dynamics, statistical models, especially Markov models, have already proved their usefulness (Usher 1992; Castellazzi et al. 2008). However, the precision of Markov models depends upon the quality of parameter estimation (Peet et al. 1992). The parameters of first-order Markov models can be tuned with the help of experts (Castellazzi et al. 2008). They can also be automatically estimated by means of algorithms such as the Baum-Welch algorithm (Welch 2003) when dealing with Hidden Markov Models (HMMs). In addition, compared to a first-order HMM, a higher-order HMM can adequately assign a probability to longer successions of land-use categories and reveal some temporal patterns.

In this paper, we propose a unified Markovian framework to :

1. represent both spatial and temporal dependencies in sites, and; 
2. cluster a territory into patches where the successions of land-use categories are drawn by a higher-order Markov process.

Our main objective is to develop a generic method aimed at describing agricultural landscapes through cropping system patterns. As Moonen and $\mathrm{B}^{\wedge}$ rberi (2008) emphasize the importance of territorial organization as a determinant of functional biodiversity, two applications of these patterns are :

1. to help understand environmental and natural processes in crop regions in Europe in relation with the organization and dynamics of agricultural landscapes, and ;

2. to develop a knowledge of agricultural dynamics, which may facilitate political decision-making and forecasting.

After presenting the characteristics of the landscape we studied, we will give a brief theoretical background of our research procedure. Then, we explain this procedure in two stages. The first stage aims at modelling the diversity of the cropping systems, independently from their location within the landscape. The second stage is focused on the localization of these cropping systems that have been revealed in the previous stage. We propose to build a temporospatial analysis through spatial analysis of crops dynamics. This approach links together the temporal and the spatial dimensions of the agricultural organization. Its implications and perspectives are discussed in an illustrative example drawn from the Niort Plain by assessing the relationship between the agricultural landscape patterns and the distribution of Montagu's Harrier nests.

\section{Methods}

\subsection{Study area}

We apply our landscape regularity modelling method on one grain-growing area in France : the Niort Plain situated within the plain of NiortBrioux, south of DeuxSèvres in Poitou-Charentes region (46.2 N, 0.4 W).

Since 1994, the Chizé Centre for Biological Studies (CNRS ${ }^{1}$ unit) has been conducting a research program on the impact of farm management strategies on biodiversity in grain growing plains. This program focuses on the NiortBrioux plain $\left(350 \mathrm{~km}^{2}\right)$. It examines the contribution of grasslands to the conservation of various species of birds in a way compatible with an

\footnotetext{
${ }^{1}$ Centre National de la Recherche Scientifique
} 
economically viable farming activity. Since the beginning of this research program, the surveyed zone has been progressively enlarged : $20 \mathrm{~km}^{2}$ in 1994, $200 \mathrm{~km}^{2}$ in $1995,320 \mathrm{~km}^{2}$ in 1996 with a relative stabilization until 2005 followed by other enlargements to $420 \mathrm{~km}^{2}$ in 2006 and to $430 \mathrm{~km}^{2}$ in 2007. In this paper, we consider the period of 12 successive years starting in 1996.

\subsection{The long-term land-use survey}

In the framework of its biodiversity research program in relation with agricultural practices, the Chizé Centre for Biological Studies $\left(\mathrm{CEBC}^{2}\right)$ carries out, every year, two land-use surveys (in April and June). These two yearly surveys take into account both early harvested and late planted crops. In each survey, the occupancy of parcels is noted down distinguishing 47 land-uses (42 agricultural land-uses, 3 urban land-uses and 2 forest landuses) as detailed in Table 1. Each parcel contains one type of crop and its physical boundaries can be a river, a path or a field limit. Each year, surveyors also update the parcel limits when a change is observed. The changing limits of the agricultural parcels led to the definition of elementary parcels, which resulted from a spatial union of previously updated parcel limits. The study area contains 19,000 elementary parcels, covering an area of $430 \mathrm{~km}^{2}$. The collected data is stored in a GIS geodatabase, in vector format.

\subsection{Theoretical background}

\subsubsection{Markov random fields and Hidden Markov Models}

Temporal and (or) spatial process can be spontaneously represented by stochastic graphs. The nodes are associated to some random variables $(X, Y)$. The $X$ s take their values from a finite set of classes

$$
\Omega=\left\{\omega_{1}, \omega_{2}, \ldots, \omega_{k}\right\}
$$

called the labels. The $Y$ s take their values from the input data - also called the observations - of the process at a specific time slot or space location. The transitions represent the temporal or spatial dependencies between the nodes. The interest of such models is to compute the a posteriori probability $P\left(X_{1}=x_{1}, X_{2}=x_{2}, \ldots, X_{n}=x_{n} \mid Y_{1}=y_{1}, Y_{2}=y_{2}, \ldots, Y_{n}=y_{n}\right)$ for a given configuration of labels $\left(x_{1}, x_{2}, \ldots, x_{n}\right)$ drawn from $\Omega$ and a set of observations $\left(y_{1}, y_{2}, \ldots, y_{n}\right)$ in order to measure how the configuration fits

\footnotetext{
${ }^{2}$ Centre National de la Recherche Scientifique, Centre d'Etudes Biologiques de Chizé
} 
the model assuming the observations. In a particular family of stochastic graphs - aka Markov Random Fields (MRF), the probability of observing $X_{i}=x_{i}$ assuming the values on all the other nodes depends on a limited set of nodes called the neighbouring nodes of $X_{i}$

$$
\begin{array}{r}
P\left(X_{i}=x_{i} \mid X_{1}=x_{1}, \ldots, X_{j \neq i}=x_{j}, \ldots, X_{n}=x_{n}\right) \\
=P\left(X_{i}=x_{i} \mid\left\{X_{\text {neighbour of } i}=x_{i}\right\}\right)
\end{array}
$$

In this paper, we present our work using second-order Hidden Markov Models (HMM2) to approximate MRF. We rely on the assumption that the distribution of land-use categories in an area at time $\mathrm{t}$ - the blocking plan - depends on the blocking plan observed at time $t-1$ or $t-2$ according to the order of the model (first-order or second-order). Hidden Markov Models analyze one dimensional sequences of observations. They differ from Markov chains (Castellazzi et al. 2008) through the presence of a supplementary hidden layer of nodes that models the structure of the data. This hidden layer is a second-order Markov chain that governs the sequence of random variables capturing the variability of the observations. Hidden Markov Models have been successfully introduced in 1976 in speech recognition (Jelinek 1976), image processing (Benmiloud and Pieczynski 1995), biology (Hughey and Krogh 1996), and ecology (Le Ber et al. 2006). They can be used adequately to model temporal and spatial stochastic processes.

In order to model MRFs, Benmiloud and Pieczinski (1995) have proposed a method to convert a spatial representation of the data into a one dimensional sequence by means of a fractal curve - the Hilbert Peano curve - that spans the two dimensional space. Two points that are close to one another on the curve are close in the plane. The opposite is not true. Despite this drawback, they show that the classical HMM training algorithms give performances comparable to the more complicated algorithms involved in Markov Random Fields.

\subsubsection{HMM2 definitions}

An HMM2 is defined by :

- A set $S=\left\{s_{1}, s_{2}, \ldots, s_{N}\right\}$ of $N$ states that are the outcomes of the variables $X_{t}$, where $t=1, \ldots, T$

- A transition matrix $A=\left(a_{i j k}\right)$ over $S^{3}$, where $a_{i j k}$ is the a priori transition probability $P\left(X_{t}=s_{k} \mid X_{t-2}=s_{i}, X_{t-1}=s_{j}\right)$ for the hidden Markov chain to be in state $s_{k}$ at index $t$ assuming it was in state $s_{j}$ at index $t-1$ and $s_{i}$ at index $t-2$. The Markov assumption states that these probabilities do not depend on index $t$. 
- A set of $N$ discrete distributions : $b_{i}($.$) is the distribution of observa-$ tions associated with state $s_{i}$. This distribution may be parametric, non parametric or even given by a HMM in a hierarchical HMM.

\subsubsection{HMM2 properties}

The second-order Hidden Markov Models are based on the probability and statistics theories. They implement an unsupervised training algorithm - the Baum-Welch algorithm - that estimates the HMM2 parameters from a corpus of observations. The estimated model enables to segment each sequence in stationary and transient parts and to build up a classification together with its a posteriori probability

$$
P(X=\text { configuration } \mid Y=\text { observations }) \text {. }
$$

In a first-order HMM, the probability that a sequence of $n$ observations - called the state duration probability - is captured by state $i$ follows a geometric decay defined by $\left(a_{i i}\right)^{n}$, where $a_{i i}$ is the a priori probability of the loop over state $i$. In a second-order HMM, the state duration is governed by two parameters, i.e. the probability of entering a state only once, and the probability of visiting a state at least twice, with the latter modelled as a geometric decay. This distribution better fits a probability density of durations than the exponential distribution of a first-order HMM. This property is of great interest when a HMM2 models a process in which a state captures only one or two observations (Mari et al. 1997).

Furthermore, the very success of HMMs is their robustness. Even when the input data do not fit a given HMM, it can give interesting results by discovering spatial and temporal regularities.

\subsubsection{Hierarchical HMM (HHMM)}

We model the spatial structure of the landscape by a MRF whose sites are random land-use sequences. These sequences are modelled by a temporal HMM2. This leads to the definition of a hierarchical HMM where a master HMM2 approximates the MRF. Then, the probability of a temporal landuse sequence is given by a temporal HMM2 as fully described by Fine et al. (1998) and Mari and Le Ber (2006). This hierarchical HMM is used to segment a landscape into regions. The temporal evolutions of the regional sites are land-use sequences that are modelled by a temporal HMM2. The use of hierarchical HMM in data mining is a special case of stochastic models as described by Le Ber et al. (2006) and may be summarized as the following steps : 
1. Specify the topology of a hierarchical HMM;

2. Gather spatio-temporal data;

3. Train the HMM on these data using the Baum-Welch algorithm;

4. Segment the data and interpret the content of the classes;

5. Design a new model and go back to step 1.

\subsubsection{ArpentAge : a data mining Software}

ArpentAGE ${ }^{3}$ (Analyse de Régularités dans les Paysages : Environnement, Territoires, Agronomie = Landscape Regularities Analysis : Environment, Territories and Agronomy) is an acronym that also means landscape surveying in French. It is the name of our knowledge discovery system based on higher-order hidden Markov models for analyzing spatio-temporal data bases. It takes as input an array of discrete data - the rows represent the spatial sites, the columns represent the time slots - and clusters the territory into patches whose crop sequences are extracted. This software allows the user to specify the architecture of the Markov model according to his objectives and the data. Displaying tools and the generation of shape files have also been implemented. The results of ARPEntAgE are interpreted and validated by domain specialists (i.e. agronomists).

\subsection{A computer limitation issue when dealing with huge amount of data}

Using a Hilbert-Peano fractal curve requires regularly spaced input data points. This is why we rasterized land-use data by following a systematic and regular sampling pattern $(10 \mathrm{~m} \times 10 \mathrm{~m})$. Data were then formatted so that the rows represent the spatial sites (sampled points) and the columns the time slots of attributes. A huge corpus with around 8 million rows has been obtained. However, the estimation of HMM2's parameters is a memory consuming process that can saturate even large computer memories. In order to help reduce the requirement of the memory resources, we choose to control two factors : (i) the length of the elementary LUS, and (ii) the size of the corpus of observations through the sampling resolution.

\footnotetext{
${ }^{3}$ http ://www.loria.fr/ jfmari/App/
} 


\section{Results}

\subsection{Preliminaries : scaling the method to deal with huge amounts of data}

\subsubsection{Choice of the succession length}

The length of Land-Use Successions (LUS) influences the interpretability of the final model. The longer the succession is, the more useful it is for agronomists. However, the total number of LUS is a power function of these succession lengths. Memory resources required during the estimation of HMM2 parameters increase with large numbers of LUS.

To help decide on the succession length, we compared the diversity of LUS between field-collected data and randomly generated data for different lengths of successions (Figure 1). In the Niort Plain case, we can see that a 4-year succession length begins to differentiate from the random case. This reinforced our choice of the quadrennial succession as the elementary observation symbol in modelling the Niort Plain case study. Further down in this paper, the 4-year LUS will be sometimes referred to as quadruplets.

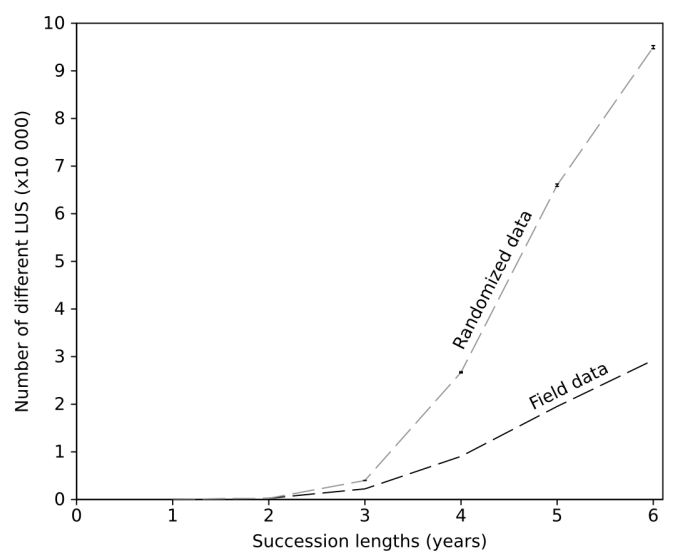

FIG. 1 - Compared diversity of LUS between field-collected data and 10 random generated data sets for different succession lengths

\subsubsection{Choice of the spatial resolution}

At regional scales, high-resolution samplings generate large amounts of data. With such amounts of input data, only rough models can be tested. 
On the other hand, with coarse resolution samplings, small parcels are omitted. In order to have an objective criterion for choosing the optimal spatial resolution, information loss in terms of LUS diversity was estimated for increasingly coarse resolution samplings. Figure 2 shows curves for the three considered LUS lengths that follow quite similar trends. As a compromise, we chose the $(80 \mathrm{~m} \times 80 \mathrm{~m})$ resolution that led to a corpus 64 times smaller than the original one, with only a loss of $6 \%$ in information diversity.

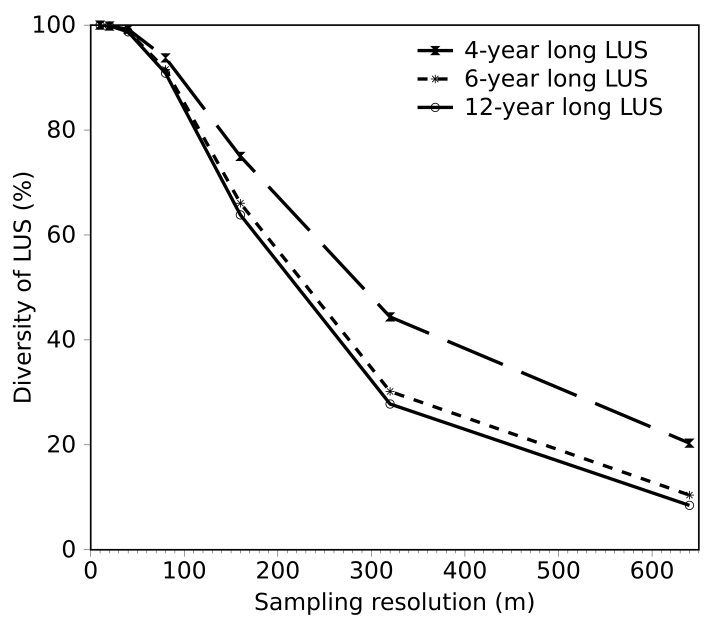

FIG. 2 - Information loss in terms of LUS diversity in relation to sampling resolutions for three succession lengths. Tested resolutions are : 10, 20, 40, $80,160,320$ and $640 \mathrm{~m}$. Irregularity in sampling intervals is dictated by an algorithmic constraint, the resolution must be proportional to a power of 2 . The most precise resolution is considered as the reference $(100 \%)$

\subsection{Modelling the diversity of farming activity within land- scapes}

The approaches to model the diversity of farming activities differ according to whether one is considering the production system or the cropping system. Numerous classification models represent the diversity of agricultural production systems in a given region, the choice of which depends significantly on the time and space scales investigated. On the other hand, few models have been developed to represent the diversity of cropping systems on a regional scale. Here we propose an approach to model this diversity by 
first dealing with the Land-Use Successions (LUS) and then their locations.

\subsubsection{The model representing the location of the diversity of LUS}

The aim is to identify temporal stabilities in Land-Use Successions, and to locate them in landscapes. The first step was to build a typology of homogeneous land-use categories (Table 1). Then, we identified the successions in our landscape (Table 2). The third step identified the dynamics of LUS (Table 3 and Figure 3). The fourth step identified patches of LUS (Figure 4 and Figure 5).

\subsubsection{Land-use typology}

In this first step we identified the major land-uses and classified them into homogeneous categories. Based on an arbitrarily frequency defined threshold (0.01 i.e. $1 \%$ of a given land-use among the total number of all land-use records in the data set), the land-use types were differentiated into major $(>0.01)$ and minor $(<0.01)$ land-uses. Then, major land-uses were grouped with other similar major or minor land-uses to form homogeneous land-use categories (hereafter called "main land-use categories"). Finally, the remaining minor land-uses were grouped into a residual category called "Others". This last land-use category is rather heterogeneous and will not be considered as a main land-use category in the following. Table 1 shows the result of this classification.

\begin{tabular}{|l|l|l|l|}
\hline $\begin{array}{l}\text { Land-use } \\
\text { category }\end{array}$ & Land-use & $\begin{array}{l}\text { Frequency } \\
\text { (Confidence, } \\
\mathrm{P}=0.05)\end{array}$ & $\begin{array}{l}\text { Cumulative } \\
\text { frequency }\end{array}$ \\
\hline $\begin{array}{l}\text { Wheat } \\
(\mathrm{W})\end{array}$ & $\begin{array}{l}\text { wheat, bearded wheat, ce- } \\
\text { real }\end{array}$ & 0.337 & 0.337 \\
\hline $\begin{array}{l}\text { Sunflower } \\
(\mathrm{S})\end{array}$ & $\begin{array}{l}\text { sunflower, ryegrass followed } \\
\text { by sunflower }\end{array}$ & 0.139 & 0.476 \\
\hline $\begin{array}{l}\text { Rapeseed } \\
(\mathrm{R})\end{array}$ & rapeseed & $0.124( \pm 0.001)$ & 0.600 \\
\hline Urban (U) & built area, peri-village, road & $0.096( \pm 0.001)$ & 0.696 \\
\hline
\end{tabular}

\footnotetext{
${ }^{4}$ Cereal is used when the species can not be identified by the surveyor (it can be wheat, barley, ryegrass or other)
} 


\begin{tabular}{|c|c|c|c|}
\hline $\begin{array}{l}\text { Grassland } \\
\text { and alfalfa } \\
\text { (G) }\end{array}$ & $\begin{array}{l}\text { permanent } \text { grassland, } \\
\text { grassland first year, tempo- } \\
\text { rary grassland (2-3 years), } \\
\text { grassland of unknown age, } \\
\text { alfalfa } 1^{\text {st }} \text { year, alfalfa } \\
2^{\text {nd }} \text { year, alfalfa } 3^{\text {rd }} \text { year, } \\
\text { alfalfa more than } 3 \text { years }\end{array}$ & $0.078( \pm 0.001)$ & 0.774 \\
\hline Maize $(\mathrm{M})$ & $\begin{array}{l}\text { maize, rye grass followed by } \\
\text { maize }\end{array}$ & $0.076( \pm 0.001)$ & 0.850 \\
\hline $\begin{array}{l}\text { Forest and } \\
\text { wasteland } \\
(\mathrm{F})\end{array}$ & forest or hedge, wasteland & $0.034( \pm 0.001)$ & 0.884 \\
\hline $\begin{array}{l}\text { Winter } \\
\text { barley }(\mathrm{B})\end{array}$ & winter barley & $0.034( \pm 0.001)$ & 0.918 \\
\hline $\begin{array}{l}\text { Ryegrass } \\
(\mathrm{Y})\end{array}$ & $\begin{array}{l}\text { ryegrass, ryegrass followed } \\
\text { by ryegrass }\end{array}$ & $0.024( \pm 0.001)$ & 0.942 \\
\hline Pea $(\mathrm{P})$ & pea & $0.022( \pm 0.001)$ & 0.964 \\
\hline Others $(\mathrm{O})$ & $\begin{array}{l}\text { spring barley, grape vine, } \\
\text { spontaneous fallow in June, } \\
\text { foxtail millet, flax, oat, clo- } \\
\text { ver, field bean, rye grass fol- } \\
\text { lowed by tillage, rye grass } \\
\text { followed by unknown, spon- } \\
\text { taneous fallow followed by } \\
\text { tillage, rye, cereal-legume } \\
\text { mixture, spring crop, mus- } \\
\text { tard, garden/market garde- } \\
\text { ning, sorghum/millet, sorg- } \\
\text { hum, millet, tillage, to- } \\
\text { bacco, other crop }\end{array}$ & $0.036( \pm 0.001)$ & 1.00 \\
\hline
\end{tabular}

TAB. 1: Composition and average frequencies of adopted land-use categories. The "Frequency" refers to the average for the total area covered by all land-uses of a given land-use category. This average was computed over a 12 year period 


\subsubsection{The conceptual model representing the diversity of LUS}

Using 4-year long LUS to model the Niort Plain landscape required the reduction of the large number of these successions (many thousands, see Figure 1). Most of the time, in the study period, the 10 main land-use categories almost describe the whole area of the Niort Plain (over 96\%, see Table 1). On this basis, we chose to represent the diversity of LUS in as many classes as there are main land-use categories. Table 2 represents the search pattern used to extract all the successions involving a given main land-use category. For each main land-use category X, we look for the list $\mathrm{S}(\mathrm{X})$ of quadruplets in which $\mathrm{X}$ was involved.

\begin{tabular}{|l|l|l|l|}
\hline $1^{\text {st }}$ Year & $2^{\text {nd }}$ Year & $3^{\text {rd }}$ Year & $4^{\text {th }}$ Year \\
\hline $\mathrm{X}$ & $?$ & $?$ & $?$ \\
\hline$?$ & $\mathrm{X}$ & $?$ & $?$ \\
\hline$?$ & $?$ & $\mathrm{X}$ & $?$ \\
\hline$?$ & $?$ & $?$ & $\mathrm{X}$ \\
\hline
\end{tabular}

TAB. 2: Search pattern for extracting all 4-year long LUS involving one of the main land-use categories. $\mathrm{X}$ represents the current main land-use category, and? any land-use category

Actually, Wheat (W), Sunflower (S) and Rapeseed (R) are generally integrated in a same succession (such as S-W-R-W, S-W-S-W, R-W-R-W, $\mathrm{S}-\mathrm{W}-\mathrm{W}-\mathrm{W}, \mathrm{R}-\mathrm{W}-\mathrm{W}-\mathrm{W}$, etc.). So, making a common class of these three crops allowed better results. To deal with this case, the above notation can be generalized to : $\mathrm{S}(\mathrm{X}, \mathrm{Y}, \ldots)$ to denote the class of successions that involve at least one of the main land-use categories $\mathrm{X}$, Y, etc.

We listed the resulting classes of successions as quadruplets "of interest" that we quantified by their frequency in the data corpus. The large number of quadruplets can then be reduced by using an appropriate threshold of cumulative frequency or by choosing a given number of most frequent quadruplets.

\subsubsection{The LUS temporal dynamics analysis by means of HMM2}

Table 3 shows the results of the temporal data mining analysis performed by the search patterns described in Table 2. Table 3 summarizes the distribution of quadruplets within the resulting classes of LUS.

Classes $\mathbf{S}(\mathbf{U})$ and $\mathbf{S}(\mathbf{F})$ are stable classes, they are mainly represented by only one quadruplet : U-U-U-U and F-F-F-F respectively. 


\begin{tabular}{|c|c|c|c|c|c|c|c|c|c|}
\hline \multicolumn{2}{|c|}{$\mathrm{S}(\mathrm{O})$} & \multicolumn{2}{|c|}{$\mathrm{S}(\mathrm{W}, \mathrm{S}, \mathrm{R})$} & \multicolumn{2}{|c|}{$\mathrm{S}(\mathrm{B})$} & \multicolumn{2}{|c|}{$\mathrm{S}(\mathrm{U})$} & \multicolumn{2}{|c|}{$\mathrm{S}(\mathrm{M})$} \\
\hline O-O-O-O & 0.079 & S-W-R-W & 0.128 & W-B-R-W & 0.056 & U-U-U-U & 0.977 & M-M-M-M & 0.155 \\
\hline W-R-W-O & 0.065 & R-W-S-W & 0.112 & W-B-S-W & 0.055 & W-U-U-U & 0.002 & M-W-M-W & 0.055 \\
\hline W-S-W-O & 0.055 & W-S-W-R & 0.112 & W-R-W-B & 0.045 & U-U-U-W & 0.002 & W-M-W-M & 0.041 \\
\hline S-W-O-W & 0.029 & W-R-W-S & 0.105 & W-S-W-B & 0.034 & G-U-U-U & 0.002 & M-W-S-W & 0.030 \\
\hline R-W-O-W & 0.027 & S-W-S-W & 0.072 & B-S-W-R & 0. & S-W-U-U & 0.001 & M-M-M-W & 0.030 \\
\hline W-O-S-W & 0.026 & R-W-R-W & 0.065 & B-R-W-S & 0.030 & U-W-U-U & 0.001 & W-S-W-M & 0.029 \\
\hline W-O-R-W & 0.025 & W-R-W-R & 0.062 & R-W-B-R & 0.026 & U-U-W-U & 0.001 & M-M-W-M & 0.028 \\
\hline O-W-S-W & 0.023 & W-S-W-S & 0.059 & S-W-B-R & 0.024 & S-U-U-U & 0.001 & S-W-M-W & 0.026 \\
\hline W-O-W-S & 0.021 & W-R-W-W & 0.033 & S-W-B-S & 0.024 & G-G-U-U & 0.001 & M-W-R-W & 0.024 \\
\hline R-W-O-R & 0.019 & W-W-R-W & 0.029 & R-W-B-S & 0.020 & U-U-U-G & 0.001 & W-M-W-S & 0.024 \\
\hline
\end{tabular}

\begin{tabular}{|c|c|c|c|c|c|c|c|}
\hline \multicolumn{2}{|c|}{$S(G)$} & \multicolumn{2}{|c|}{$S(F)$} & \multicolumn{2}{|c|}{$\mathrm{S}(\mathrm{Y})$} & \multicolumn{2}{|c|}{$\mathrm{S}(\mathrm{P})$} \\
\hline G-G-G-G & 0.377 & F-F-F-F & 0.983 & W-R-W-Y & 0.045 & P-W-R-W & 0.052 \\
\hline G-G-G-W & 0.040 & F-F-F-W & 0.002 & W-S-W-Y & 0.039 & M-P-W-M & 0.038 \\
\hline W-G-G-G & 0.026 & G-F-F-F & 0.001 & W-Y-S-W & 0.038 & W-P-W-R & 0.033 \\
\hline Y-G-G-G & 0.026 & G-G-F-F & 0.001 & S-W-Y-W & 0.028 & P-W-S-W & 0.031 \\
\hline S-G-G-G & 0.025 & F-F-F-S & 0.001 & Y-W-S-W & 0.026 & R-W-P-W & 0.029 \\
\hline W-S-G-G & 0.018 & F-F-F-M & 0.001 & W-Y-W-S & 0.025 & W-S-W-P & 0.027 \\
\hline G-G-G-S & 0.016 & F-F-M-M & 0.001 & R-W-Y-W & 0.023 & W-R-W-P & 0.026 \\
\hline G-G-S-W & 0.015 & F-F-F-G & 0.001 & W-Y-W-R & 0.019 & M-M-P-W & 0.026 \\
\hline O-G-G-G & 0.015 & $Y-F-F-F$ & 0.001 & $W-Y-W-Y$ & 0.019 & S-W-P-W & 0.026 \\
\hline G-G-W-R & 0.013 & F-F-O-W & 0.000 & Y-W-R-W & 0.018 & P-W-M-M & 0.022 \\
\hline
\end{tabular}

TAB. 3 - Results of the temporal analysis for the Niort Plain case study over the 1996-2007 period : frequency distribution of LUS for each class of successions 
$\mathbf{S}(\mathbf{W}, \mathbf{S}, \mathbf{R})$ is the most dominant class. Its quadruplet distribution allows the deduction of principal rotations such as : (i) "S-W-R-W" which is a quadrennial rotation composed of the four circular permutations of quadruplets : S-W-R-W, R-W-S-W, W-S-W-R, W-R-W-S. Its frequency is around $40 \%$; and (ii) "S-W" and "R-W" : which are two biennial rotations deduced from the quadruplets : S-W-S-W, W-S-W-S and R-W-R-W, W-R-W-R respectively. Their frequencies are slightly over $10 \%$. These three rotations represent around $60 \%$ of the total composition of the $\mathrm{S}(\mathrm{W}, \mathrm{S}, \mathrm{R})$ class.

$\mathbf{S}(\mathbf{B}), \mathbf{S}(\mathbf{M}), \mathbf{S}(\mathbf{G}), \mathbf{S}(\mathbf{Y})$ and $\mathbf{S}(\mathbf{P})$ are less ordered classes and somehow reflect the farmers' "freedom" as to their land allocation with the corresponding categories of crops (namely winter Barley (B), Maize $(\mathrm{M})$, Grassland and alfalfa $(\mathrm{G})$, rYegrass $(\mathrm{Y})$ and Pea $(\mathrm{P})$ ). This corroborates our choice in considering the succession classes $-\mathrm{S}(\mathrm{X})$ - as the regularities to be located in the next step, rather than considering rotations.

$\mathbf{S}(\mathbf{M})$ : In this class, the quadruplet distribution allows to deduce 3 main regularities : (i) $15 \%$ of the maize monoculture shown by the M-MM-M quadruplet, and (ii) about $10 \%$ of the biennial rotation WM deduced from the quadruplets $\mathrm{M}-\mathrm{W}-\mathrm{M}-\mathrm{W}$ and $\mathrm{W}-\mathrm{M}-\mathrm{W}-\mathrm{M}$, and (iii) about $0.8 \%$ of the quadrennial rotation "M-W-S-W".

$\mathbf{S}(\mathbf{P})$ : In this class, the quadruplet distribution shows the quadrennial rotations "PWRW" and "PWSW" whose respective frequencies are roughly $10 \%$.

$\mathbf{S}(\mathbf{B})$ : In class, the quadruplets distribution shows two triennial rotations "RWB" and "SWB" whose respective frequencies are around $10 \%$.

$\mathbf{S}(\mathbf{O})$ : In this class, the O-O-O-O LUS characterizes the parcels covered by vineyards or market-garden crops that, mainly, keep the same land cover during all the study period. Other quadruplets incorporating a $\mathrm{O}$ appear with lower frequencies and reflect that this land cover can appear randomly in numerous parcels. The mean blocking plan of the $\mathrm{O}$ occupation is roughly $3 \%$ over the 12 year study period. Therefore $\mathrm{O}$ occupations disappear in the amount of $\mathrm{W}, \mathrm{S}, \mathrm{R}$ in these parcels because the $\mathrm{O}$ occupations are not integrated in some specific rotations. This leads to a distribution's estimation almost equal to the $\mathrm{S}(\mathrm{W}, \mathrm{S}, \mathrm{R})$ distribution. We found this result by computing the divergence between these two distributions and found them close to each other. 


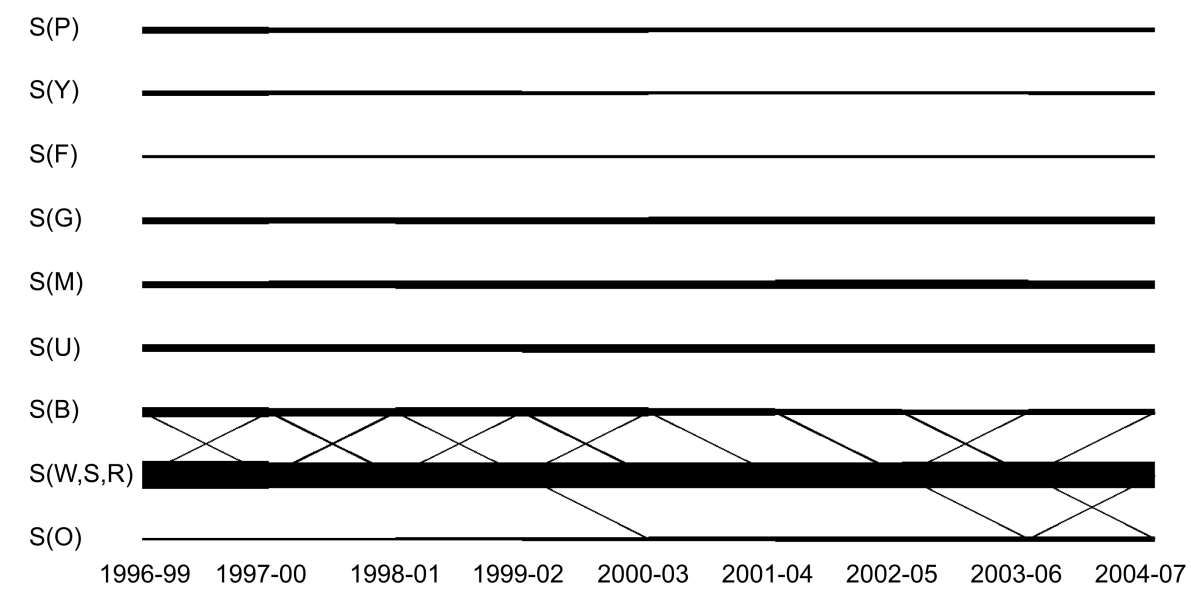

FIG. 3 - Results of the temporal analysis for the Niort Plain case study over the 1996-2007 period : Markov diagram shows the temporal dynamics of LUS classes after 50 iterations of the EM algorithm. The x-axis represents the study period divided into sub periods of 4 years. The y-axis represents the classes of LUS involving: Wheat (W), Sunflower (S), Rapeseed (R), Urban (U), Maize (M), Grassland and alfalfa (G), Forest and wasteland $(\mathrm{F})$, winter Barley (B), rYegrass $(\mathrm{Y})$, and Pea $(\mathrm{P})$. Others $(\mathrm{O})$ is a residual land-use category that contains successions of less frequent land-use types. Diagonal transitions stand for inter-annual changes. Horizontal transitions indicate inter-annual stability. Only transitions whose frequencies are greater than 0.01 are displayed. The line width reflects the a posteriori probability of the transition assuming the observation of the 12-year LUS. 
Figure 3 shows the dynamics of the resulting classes of LUS in the Markov diagram. The quite constant width of horizontal lines of the Markov diagram indicates that during the whole study period (1996-2007), no major change has affected the dynamics of LUS. This figure shows diagonal transition lines between $\mathrm{S}(\mathrm{B})$ and $\mathrm{S}(\mathrm{W}, \mathrm{S}, \mathrm{R})$ classes and between $\mathrm{S}(\mathrm{O})$ and $\mathrm{S}(\mathrm{W}, \mathrm{S}, \mathrm{R})$. In the Niort area, Barley is cultivated in 3-year rotations ("RWB" or "SWB"). When these 3 year rotations are over, the farmers can start new rotations spanning 2 years ("RW", "SW") or 4 years ("SBRW"). The 3-year rotations are related to the horizontal lines in the $\mathrm{S}(\mathrm{B})$ class whereas transitions from a 3-year rotation to a 2- or 4-year rotation trigger a diagonal line to the $\mathrm{S}(\mathrm{W}, \mathrm{S}, \mathrm{R})$ class.

The diagonal transitions between $\mathrm{S}(\mathrm{O})$ and $\mathrm{S}(\mathrm{W}, \mathrm{S}, \mathrm{R})$ are explained by the closeness of the two distributions.

\subsubsection{The LUS spatial analysis by means of HHMM2}

In this step, temporal regularities (i.e. classes of successions) found in the temporal analysis step were localized within the Niort Plain landscape. As we observed that LUS was stationary over the 1996-2007 period, we used a simple temporal HMM2 to represent the states of the hierarchical HMM2. This temporal model does not segment the study period but rather considers it as a whole. This model has 2 states. One describes the distribution of the quadruplets of interest related to the class $\mathrm{S}(\mathrm{X})$, the other state captures the distribution of the quadruplets in the neighbourhood. The Markov field introduces a blur in the patch's frontier and in the patch estimation because a site is classified not only based on its temporal characteristics (the quadruplet succession) but depends now on the classification of the neighbouring sites. The map of the Niort Plain shown in Figure 4, is the result of the temporo-spatial Markov modelling process that defines a classification based on the LUS that have been observed between 1996 and 2007. The landscape is seen as patches of LUS. For each class of patches, there is a corresponding distribution of LUS, which is summarized in a diagram format (Figure 5).

The spatial partitioning with the HHMM2 fails to locate the $\mathrm{S}(\mathrm{O})$ class within the Niort Plain landscape. The spatial analysis located two small patches covering only $0.05 \%$ of the classified area, which correspond to six elementary parcels. For visibility and significance considerations, we did not represent the corresponding patches in the resulting map.

The class of patches labelled (a) represents the S(W,S,R) class of LUS in almost $70 \%$ of the total area. In the remaining area there are residual 


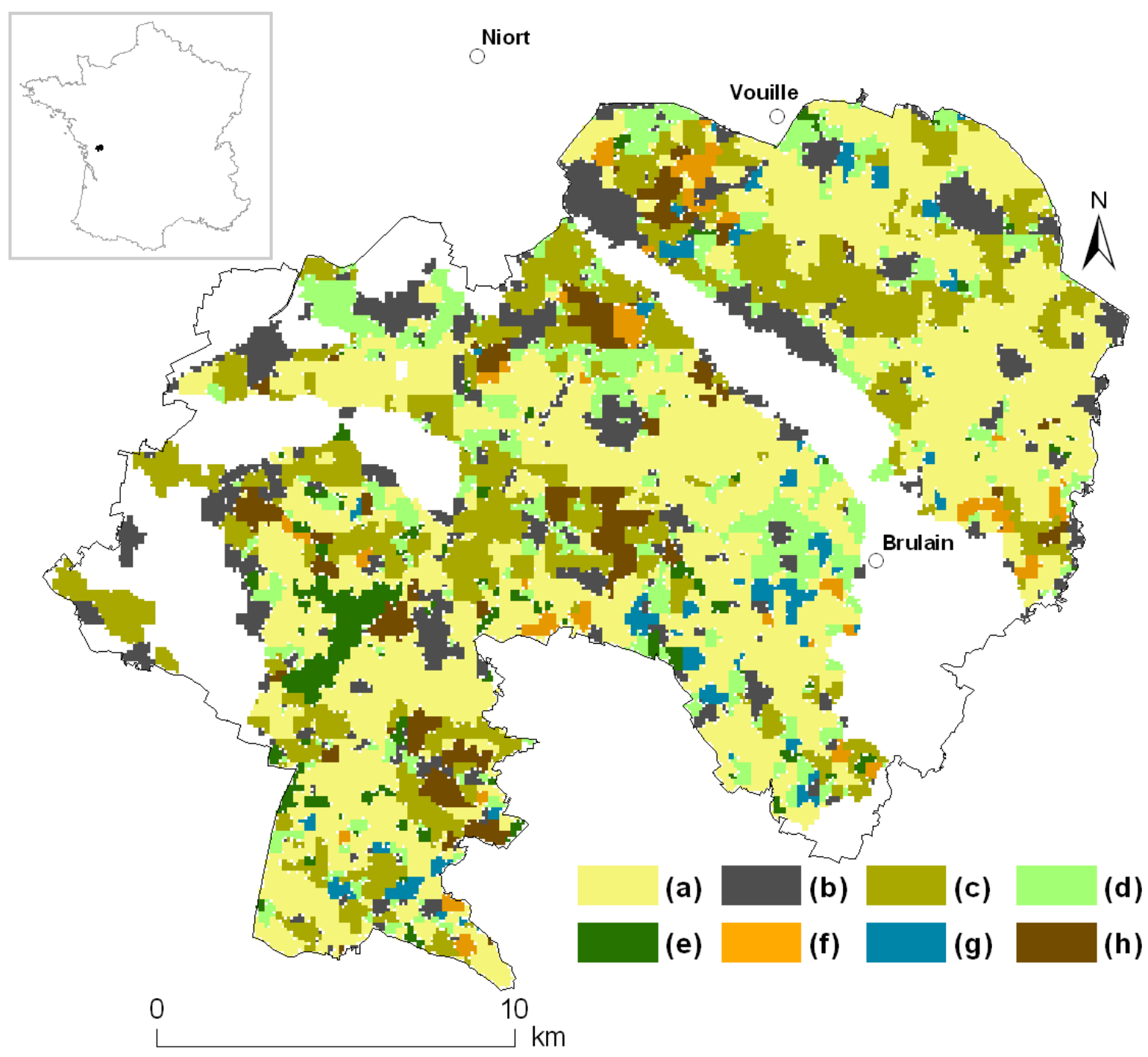

FIG. 4 - The Niort Plain landscape as patches of LUS. White areas in the map are unclassified because they were insufficiently surveyed over the 19962007 period. Location of the Niort Plain in France is depicted in the upper left-hand box. The map legend is given in Fig. 5 
(a)

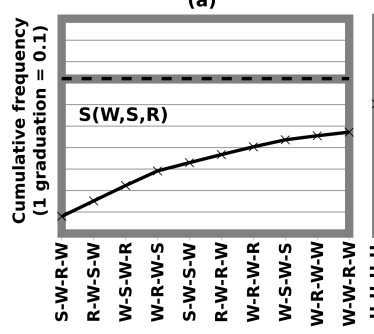

(e)

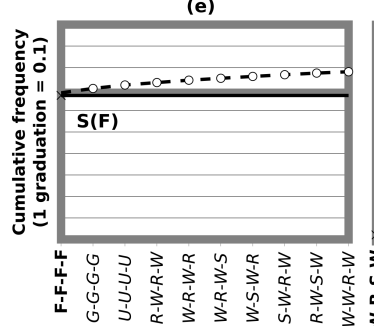

(b)

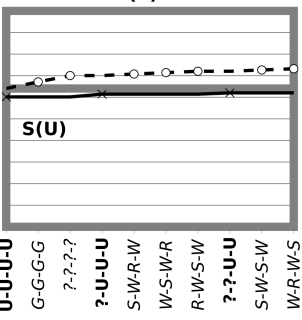

(f)

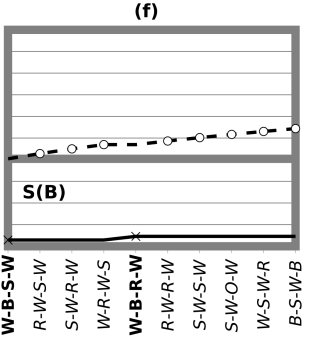

(c)

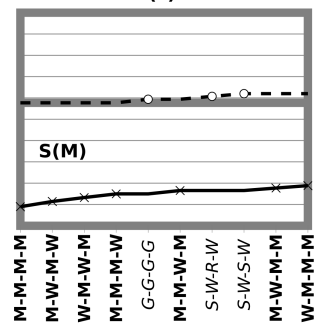

(g)

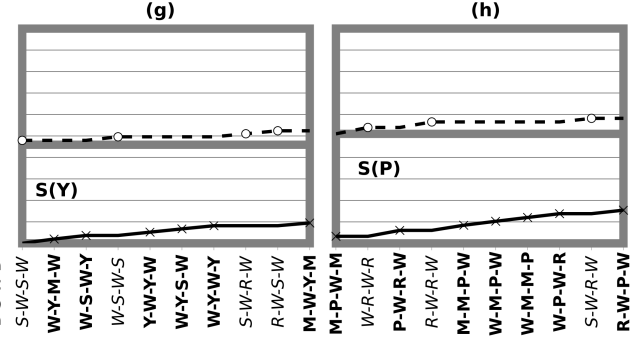

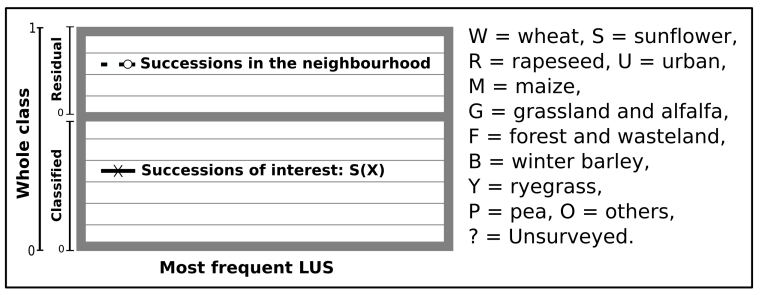

FIG. 5 - Distribution of the most frequent LUS for each class of patches shown in Figure 4. Each diagram plots separately the distribution of searched successions (lower rectangle) and residual successions (upper rectangle). The residual successions result from both smoothing patches and border effects introduced by the Markov field. Bold quadruplets belong to the successions of interest and italic quadruplets are residual successions. The frequency of each quadruplet has been computed by dividing the count of the quadruplet by the size of the class 
successions i.e. successions that contain neither Wheat nor Sunflower nor Rapeseed.

The class of patches labelled (b) represents successions in the Urban category. In this class of patches, the Urban category is present in LUS in more than $60 \%$ of the total area. The blur introduced by the Markov field can be seen in this patch. The temporal analysis exhibited a 0.975 probability for the quadruplet U-U-U-U, the Markov field lowers this probability to 0.60. The residual part is mainly populated by the quadruplets of the $S(G)$ class that are typical of urban neighbourhoods. The same influence can be seen in the $\mathrm{S}(\mathrm{G})$ class where $\mathrm{U}-\mathrm{U}-\mathrm{U}-\mathrm{U}$ is found in the residual part.

The map unit (c) represents the $\mathrm{S}(\mathrm{M})$ class of LUS in almost $60 \%$ of the total area, where around $10 \%$ has been cultivated with maize monoculture for at least 4 years (the quadruplet M-M-M-M).

The map unit $(\mathrm{d})$ represents the $\mathrm{S}(\mathrm{G})$ class of LUS in almost $50 \%$ of the total area. It is mainly composed of old pastures (20\% of G-G-G-G quadruplets), but also more recently converted to Grassland category areas (Y-G-G-G, W-G-G-G). Cropping systems using Wheat, Rapeseed and Sunflower are more likely to be found around grasslands.

The map unit (e) refers to Forest and Wasteland category in $70 \%$ of the total area of the associated patches. The only F-F-F-F quadruplet showing that Forests and Wastelands are rather stable represents this category. Close to forests, one is likely to find Grasslands, Urban areas and some cropping systems including Wheat, Rapeseed and Sunflower as shown in the residual part.

Map units (f,g,h) are less well classified. This is shown by their large residual intervals due to the neighbourhood effects. However, the corresponding patches are particularly interesting because they contain crops (respectively winter Barley (B), rYegrass (Y) and Pea (P)) whose frequency is more important than elsewhere.

\section{Discussion}

\subsection{A new framework for Landscape regularity modelling : a Time $\mathrm{x}$ Space analysis}

The main stream of our research on landscape regularities modelling consists in a Time $\mathrm{x}$ Space analysis based on a stochastic approach. We pointed out the consistency of crop sequences (Le Ber et al. 2006 ; Castellazzi et al. 2008) by a LUS temporal analysis before locating the temporal regularities in the landscape by means of HHMM2. 
The main advantages of this method are :

1. to be related with the farmers' choices since they use crop sequences instead of using a crop by crop organization,

2. to improve the landscape analysis with respect to field uses, and

3. to automatically learn the model parameters from the observation data.

In this paper, we described a new data mining method that processes a huge corpus of land-use observation data from a medium-size territory in order to :

1. choose the succession length of land-use,

2. choose the spatial resolution,

3. define a conceptual model for representing the diversity of LUS,

4. and finally, create maps that show patches of temporal regularities. These maps give an objective classification of the territory based on its pluriannual agronomic organization. They are of great interest when the ecological process under study and the spatial organization of the patches are correlated.

\subsection{The need of perennial information systems}

We used a data base built on a long term survey led by a CNRS team that involves a huge amount of human labour.

Another source of land-use maps is satellite remote sensing images, whose spatial and temporal resolutions have been greatly improved in recent years. As a common tool in Geography, it can be used to map land-uses on a regional scale (Girard et al. 1990; Veldkamp and Lambin 2001; Verburg and Veldkamp 2001). We put forward the hypothesis that our modelling method can handle those remote sensing data if they are able to inform a long time period with a sub-annual resolution.

\subsection{Linking with biodiversity resources}

To illustrate an attempt at linking agricultural patterns at a regional scale and ecological data, we chose a heritage species of birds : Montagu's Harrier. Nest locations of Montagu's Harrier overlapped the patches of LUS as depicted in Figure 6.

The joint representation of nest locations and landscape organization is useful for ecologists to formulate research issues and hypotheses related to 


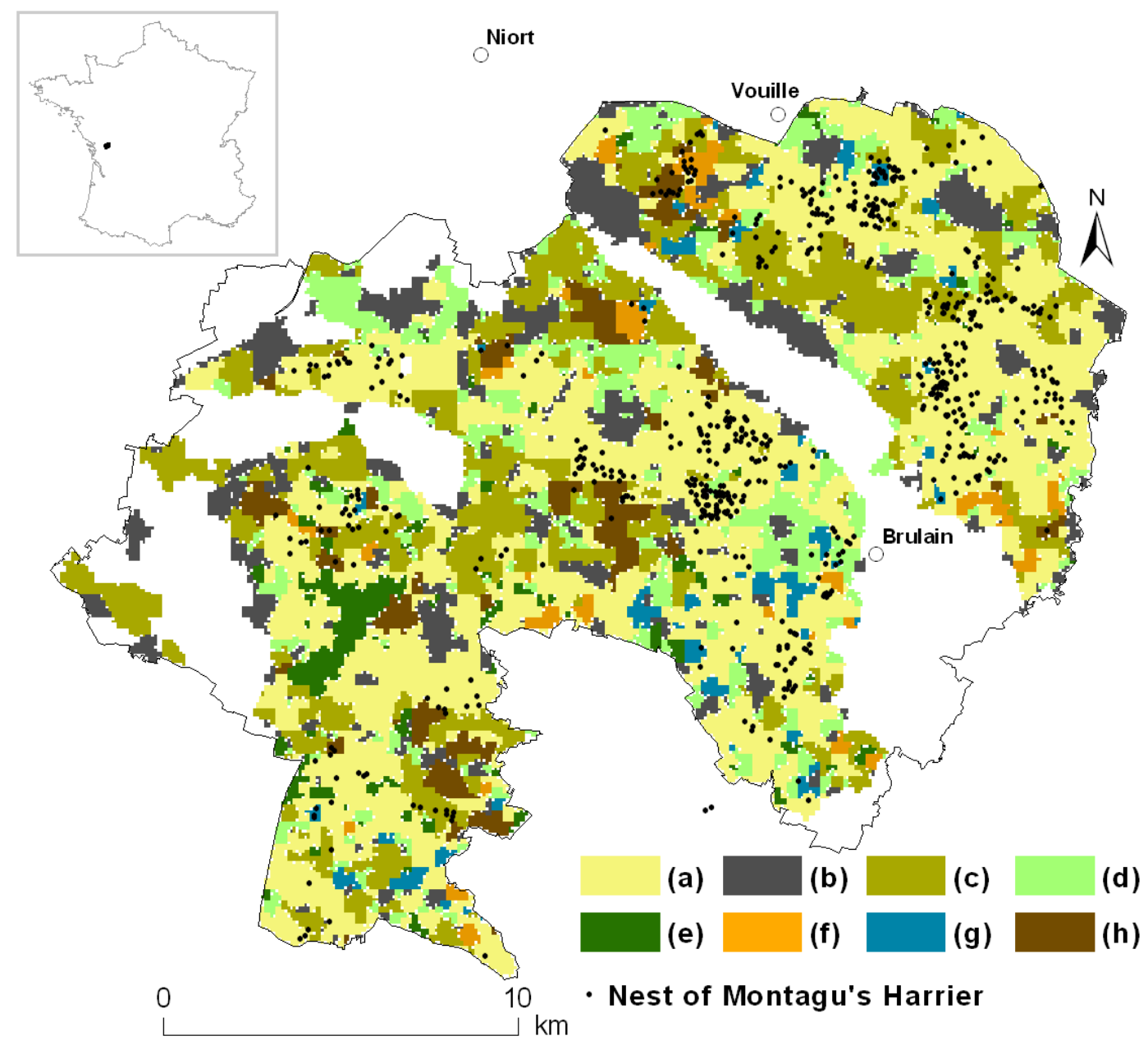

Fig. 6 - Spatial distribution of Montagu's Harrier nests (Circus pygargus) within patches of LUS. The nests belong to the 1996-2007 period, which is the same period used to define patches of LUS. The location of nests results from a comprehensive monitoring throughout the study area each year from late April to late July 


\begin{tabular}{|l|l|}
\hline \multicolumn{1}{|c|}{ Map unit } & Nests per $\mathrm{Km}^{2}$ \\
\hline a & 3.42 \\
\hline b & 0.00 \\
\hline c & 0.97 \\
\hline d & 0.51 \\
\hline e & 0.00 \\
\hline f & 1.07 \\
\hline g & 2.79 \\
\hline h & 1.38 \\
\hline
\end{tabular}

TAB. 4: Density of Montagu's Harrier nests for each map unit. The nests belong to the 1996-2007 period

this bird's distribution over the agricultural area and over a longer period than one year. For instance, one can see that while patches of class (a) are homogeneously distributed over the studied area, one can wonder why the number of nests in the South-West patches of this class is so low compared to the mean density. Ornithologists make the assumption that the presence of egg predators in the forest (patch e) prevent Montagu's Harriers from nesting in the vicinity and leads them to adopt a semi colonial behaviour. But this statistical curiosity is still an open issue.

This illustration provides only broad tendencies on the joint relationship between Montagu's Harrier and its surrounding landscape. In fact, involved territories in the Montagu's Harrier's life are substantially larger than the nesting scale (Salamolard 1997). Landscape units have to be linked with animal territories and habitats. Future works will be to evaluate the areas involved in the definition of animal territories. Ecological and agricultural pattern interactions could be more deeply explored by following an organismcentered view of landscape heterogeneity (Turner 2005). This can be achieved by coupling agricultural and ecological data in the data mining process in order to extract joint regularities of both agricultural landscape descriptors and ecological indicators. Indeed, this needs a close collaboration with ecologists. This is what we intend to investigate in our future research work. 


\subsection{Contribution of agronomy to environmental issues at regional scales : contribution of Landscape Agronomy to Landscape Ecology}

From an agronomist's point of view, we consider that agricultural landscapes are created by farmer practices (Morlon and Benoît 1990; Le Ber and Benoit 1998), and we seek to describe and to model the driving forces of landscape changes. In the present work, we hope to contribute to Landscape Agronomy which is an emerging field (Benoît et al. 2007) that holds three main scientific tasks :

1. to identify the rules and laws within the landscape that link environmental processes and farming systems;

2. to build scenarios for partners showing the implications of land-use practices for landscapes, and;

3. to build bridges between agronomists, geographers and ecologists on a common scientific field of interest : landscape.

As a contribution to Landscape Ecology, Landscape Agronomy is intended to give the "managing dimension" to the eco-field hypothesis of Farina and Belgrano (2006).

\section{Acknowledgments}

This work was supported by the ANR-ADD-COPT project, the APIECOGER project and the ANR-BiodivAgrim project. We thank the CNRS team in Chizé for their data records obtained from their "Niort Plain data base". We thank Anne Mimet and the anonymous reviewers for their useful comments.

\section{References}

Benmiloud B, Pieczynski W (1995) Estimation des paramètres dans les chaînes de Markov cachés et segmentation d'images. Traitement du signal $12: 433-454$

Benoît M, Mignolet C, Herrmann S et al (2007) Landscape as designed by farming systems : a challenge for landscape agronomists in Europe. In : Farming Systems Design 2007, Methodologies for Integrated Analysis of Farm Production Systems, Catania, 10-12 September 2007 
Benoît M, Papy F (1997) Pratiques Agricoles et qualité de l'eau sur le territoire alimentant un captage. In : Neveu A, Riou C, Bonhomme R et al (eds) L'eau dans l'espace rural (Production végétale et qualité de l'eau). Aupelf-Uref-UREF \& Inra éditions, Paris, pp 323-338

Butler SJ, Vickery JA, Norris K (2007) Farmland biodiversity and the footprint of agriculture. Science $315: 381-384$

Castellazzi M, Wood G, Burgess P et al (2008) A systematic representation of crop rotations. Agricultural Systems $97: 26-33$

De Koning GHJ, Verburg PH, Veldkamp A et al (1999) Multi-scale modelling of land use change dynamics in Ecuador. Agricultural Systems 61 :7793

Donald PF, Green RE, Heath MF (2001) Agricultural intensification and the collapse of Europe's farmland bird populations. Proceedings of the Royal Society of London $268: 25-29$

Fine S, Singer Y, Tishby N (1998) The Hierarchical Hidden Markov Model : Analysis and Applications. Machine Learning 32 :41-62

Forman RTT, Godron M (1986) Landscape ecology. John Wiley, New York

Fuller RM, Devereux BJ, Gillings S, Amable GS, Hill RA (2005) Indices of bird-habitat preference from field surveys of birds and remote sensing of land cover : a study of south-eastern England with wider implications for conservation and biodiversity assessment. Global Ecology and Biogeography $14: 223-240$

Girard CM, Benoit M, De Vaubernier E et al (1990) SPOT HRV data to discriminate grassland quality. International Journal of Remote Sensing $11: 2253-2267$

Glenn-Lewin DC, van der Maarel E (1992) Patterns and processes of vegetation dynamics. In : Peet RK, Glenn-Lewin DC, veblen TT (eds) Plant Succession : Theory and Prediction. Chapman \& Hall, London, pp 11-44

Hughey R, Krogh A (1996) Hidden Markov Models for Sequence Analysis : Extension and Analysis of the Basic Method. Computer Applications in the Biosciences $12: 95-107$

Jelinek F (1976) Continuous speech recognition by statistical methods. Proceedings of the IEEE $64: 532-556$

Lambin E, Geist H, Lepers E (2003) Dynamics of land-use and land-cover change in tropical regions. Annual Review of Environment and Resources $28: 205-241$

Landais E (1996) Typologies d'exploitations agricoles. Nouvelles questions, nouvelles méthodes. Economie Rurale (SFER) $236: 3-15$ 
Le Ber F, Benoît M (1998) Modelling the spatial organisation of land use in a farming territory. Example of a village in the Plateau lorrain. Agronomie $18: 103-115$

Le Ber F, Benoît M, Schott C et al (2006) Studying crop sequences with CarrotAge, a HMM-based data mining software. Ecological Modelling $191: 170-185$

Leisz SJ, Thu Ha N, Bich Yen N et al (2005) Developing a methodology for identifying, mapping and potentially monitoring the distribution of general farming system types in Vietnam's northern mountain region. Agricultural Systems $85: 340-363$

Mari J-F, Le Ber F (2006) Temporal and spatial data mining with second-order hidden markov models. Soft Computing 10 :406-414

Mari, J-F, Haton, J-P, Kriouile, A (1997) Automatic word recognition based on second-order Hidden Markov Models. IEEE Transactions on speech and Audio Processing $5: 22-25$

Mignolet C, Benoît M (2001) Réflexions sur une segmentation régionale selon la diversité des systèmes techniques agricoles - Cas de la plaine des Vosges. Géomatique $11: 177-190$

Mignolet C, Schott C, Benoît M (2007) Spatial dynamics of farming practices in the Seine basin : Methods for agronomic approaches on a regional scale. Science of the Total Environment 375 :13-32

Moonen A-C, B^rberi P (2008) Functionnal biodiversity : An agroecosystem approach. Agriculture, Ecosystems and Environment 127 :7-21 Morlon P, Benoît M (1990) ftude méthodologique d'un parcellaire d'exploitation agricole en tant que système. Agronomie $6: 499-508$

Peet RK, Glenn-Lewin DC, Veblen TT (1992) Plant Succession : Theory and Prediction. Chapman \& Hall

Perrot C (1990) Typologie d'exploitations construite par agrégation autour de $\mathrm{p}^{\mathrm{TM}}$ les définis ${ }^{\wedge}$ dire d'experts. Proposition méthodologique et premiers résultats obtenus en Haute-Marne. Prod Anim 3 :51-66

Poudevigne I, Alard D (1997) Landscape and agricultural patterns in rural areas : a case study in the Brionne Basin, Normandy, France. Journal of Environmental Management $50: 335-349$

Reboul C (1976) Mode de production et systèmes de culture et d'élevage. Economie Rurale $112: 55-65$

Retho B, Gaucherel C, Inchausti P et al (2008) Spatially explicit population dynamics of Pterostichus Melanarius I11. (Coleoptera : Carabidae) in response to changes in the composition and configuration of agricultural landscapes. Landscape and Urban Planning 84 :191-199 
Robinson RA, Sutherland WJ (2002) Post-war changes in arable farming and biodiversity in Great Britain. Journal of Applied Ecology 39 :157-176

Salamolard M (1997) Utilisation de l'espace par le Busard cendré Circus pygargus. Superficie et distribution des zones de chasse. Alauda $65: 307-320$

Sebillotte M (1974) Agronomie et agriculture. Essai d'analyse des tâches de l'agronome. Cahiers de l'ORSTOM $24: 3-25$

Turner MG (1990) Spatial and temporal analysis of landscape pattern. Landscape Ecology 4 : 21-30

Turner MG (2005) Landscape ecology : what is the state of the science? Annual Review of Ecology, Evolution, and Systematics 36 :319-344

Usher MB (1992) Statistical models of succession. In : Peet RK, GlennLewin DC, veblen TT (eds) Plant Succession : Theory and Prediction. Chapman \& Hall, London, pp 215-246

Veldkamp A, Fresco LO (1997) Reconstructing land use drivers and their spatial scale dependence for Costa Rica (1973 and 1984). Agricultural Systems $55: 19-43$

Veldkamp A, Lambin E (2001) Predicting land-use change. Agriculture, Ecosystems and Environment $85: 1-6$

Verburg PH, Veldkamp A (2001) The role of spatially explicit models in land-use change research : a case study for cropping patterns in China. Agriculture, Ecosystems and Environment 85 :177-190

Welch LR (2003) Hidden markov models and the baum-welch algorithm. IEEE Information Theory Society Newsletter $53: 10-13$ 